\title{
Botulinum toxin-A injection into the anterior belly of the digastric muscle for the prevention of post-operative open bite in class II malocclusions: a case report and literature review
}

\author{
Yei-Jin Kang ${ }^{1}$, Bong Kuen Cha ${ }^{2}$, Dong Soon $\mathrm{Choi}^{2}$, In San Jang ${ }^{2}$ and Seong-Gon Kim ${ }^{1 *}$ [D
}

\begin{abstract}
Background: Class II malocclusion patients with hyperdivergent facial types are characterized by short mandibular body lengths and anterior open bite. Accordingly, the treatment for hyperdivergent skeletal class II malocclusion is a lengthening of the mandibular body length and a counterclockwise rotation of the mandible. To prevent postoperative relapse, botulinum toxin-A (BTX-A) injection can be a retention modality.

Case presentation: A class II open-bite patient received BTX-A injection to the anterior belly of her digastric muscle for the prevention of post-operative relapse. The relapse was evaluated via a clinical examination and a lateral cephalometric radiograph after the completion of post-surgical orthodontic treatment. The patient showed stable occlusion without any signs of relapse at 15 months post-operatively.

Conclusion: In this case presentation, a single injection into the anterior belly of the digastric muscle was sufficient for the prevention of post-operative open bite.
\end{abstract}

Keywords: Botulinum toxin-A, Open bite, Malocclusion, Orthognathic surgery, Relapse

\section{Background}

A skeletal class II malocclusion has a short mandibular body length relative to the maxilla [1]. Accordingly, the treatment for a skeletal class II malocclusion is a lengthening of the mandibular body via ramus osteotomy. If patients have anterior open bites due to hyperdivergent facial skeletal types, a counterclockwise rotation of the mandible is also required. These types of patients have shown high rates of post-operative relapse and reduced overbite [2]. Many treatment protocols have been introduced to prevent this type of post-operative relapse.

Rigid fixation and suprahyoid myotomy are types of treatment protocols $[3,4]$. Inverted L-shaped bicortical screw fixation is considered a reliable fixation method

\footnotetext{
* Correspondence: kimsg@gwnu.ac.kr

${ }^{1}$ Department of Oral and Maxillofacial Surgery, College of Dentistry,

Gangneung-Wonju National University, Gangneung 28644, Republic of Korea Full list of author information is available at the end of the article
}

for patients with potential relapse occurrence $[5,6]$. Suprahyoid myotomy reduces muscle power that may pull the mandible downward [3]. Although suprahyoid myotomy has shown an acceptable level of success for the prevention of post-operative open bite, it is not widely used at present because of the risk of post-operative morbidity [7].

Botulinum toxin (BTX) originates from bacteria. There are several types of BTX [8]. Among them, BTX-A is the most widely used in clinical practice [9]. In the field of oral and maxillofacial plastic and reconstructive surgery, BTX-A injection is used for the treatment of temporomandibular disorder [10] and for the correction of post-traumatic open bite [11]. In case of open-bite correction, 20 units of BTX-A was injected into the anterior belly of the digastric muscle [11]. The effect of BTX-A injection occurs immediately as a decrease in muscle activity [12]. Then the muscle volume 
decreases; this usually lasts for 6 months after BTX-A is injected into the masseter muscle [13]. The greatest amount of post-operative relapse after orthognathic surgery appears within 6 months post-operatively [14]. A single injection of BTX-A into the target muscle at the time of surgery may be sufficient to prevent post-operative relapse.

In this case presentation, a class II open-bite patient received BTX-A injection to the anterior belly of her digastric muscle for the prevention of post-operative relapse. Post-operative follow-up continued for 15 months. There was no evident relapse in this patient.

\section{Case presentation}

A 21-year-old female patient was referred from the department of orthodontics to our clinic for orthognathic surgery after the completion of pre-surgical orthodontic treatment. Clinically, she showed anterior open bite with Angle's class II molar relationship. She also showed hyperplasia of the maxilla and excessive exposure of the maxillary anterior teeth at rest. Her pre-operative radiographs showed a short mandibular body length with a small SNB angle and slight maxillary canting. Her medical history was unremarkable.

The patient underwent orthognathic surgery under general anesthesia. For the maxilla, $2 \mathrm{~mm}$ of total impaction with an additional $2 \mathrm{~mm}$ of posterior impaction, and canting correction was performed using LeFort I osteotomy. For the mandible, $2 \mathrm{~mm}$ advancement with a counterclockwise rotation was performed to close the patient's anterior open bite and establish proper occlusion according to the maxillary movement. After these procedures, genioplasty was performed to establish the patient's esthetic facial contour. As the required advancement amount of genioplasty was large $(8 \mathrm{~mm})$, a double genioplasty was performed. After all of the surgical procedures, 20 units of botulinum toxin (Meditoxin Type A, Medytox, Seoul, Korea) was injected into the anterior belly of the patient's digastric muscle using a 1-cc syringe immediately after surgery (Fig. 1).

Relapse was evaluated via a clinical examination and a lateral cephalometric radiograph after the completion of the post-surgical orthodontic treatment. The patient's overbite was $1.9 \mathrm{~mm}$ immediately after surgery and 3.2 mm 15 months post-operatively (Table 1 ). Her overjet was $3.9 \mathrm{~mm}$ immediately after surgery and $3.7 \mathrm{~mm} 15$ months post-operatively (Table 1 ). The patient showed stable occlusion without any signs of relapse (Fig. 2) and was satisfied with the esthetic results.

\section{Discussion}

Hyperdivergent skeletal class II malocclusion with anterior open bite is challenging because of the high occurrence of post-operative relapse [2]. Accordingly, this was an indication for BTX-A therapy. In this case, BTX-A injection into the anterior belly of the digastric muscle seemed to prevent post-operative open bite. The patient's overbite was successfully maintained for 15 months post-operatively. The SNB angle and mandibular plane angle were also stable post-operatively (Fig. 2). Considering that BTX-A injection was simple and the procedure has a low rate of complications, BTX-A injection into the anterior belly of the digastric muscle may be considered an additional procedure for the prevention of post-operative anterior open bite [15].

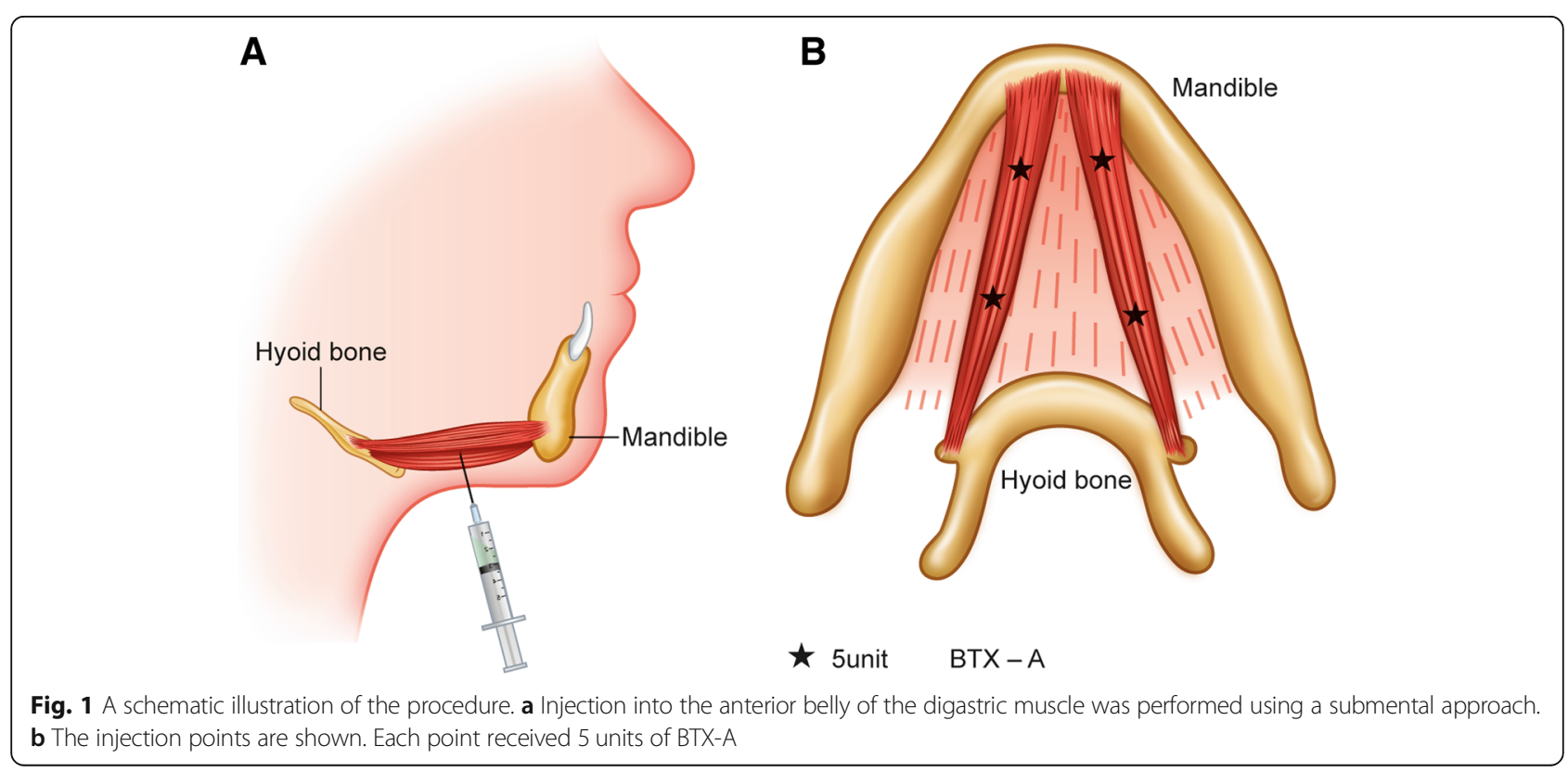


Table 1 Summary of the patient's cephalometric measurements

\begin{tabular}{|c|c|c|c|}
\hline Measurement & Pre-operative & Immediate & 15 months later \\
\hline \multicolumn{4}{|l|}{ 1. Sagittal relation } \\
\hline SNA (deg) & 75.0 & 77.6 & 75.9 \\
\hline SNB (deg) & 67.3 & 73.7 & 70.7 \\
\hline ANB (deg) & 7.7 & 2.4 & 4.7 \\
\hline Mandibular length (mm) & 109.2 & 116.9 & 117.3 \\
\hline Midfacial length (mm) & 82.9 & 88.2 & 86.4 \\
\hline \multicolumn{4}{|l|}{ 2. Vertical relation } \\
\hline Mandibular plane (deg) & 47.3 & 35.7 & 41.3 \\
\hline Occlusal plane SN (deg) & 28.9 & 26.0 & 28.9 \\
\hline Palatal plane angle (deg) & 7.2 & 8.0 & 7.3 \\
\hline Gonial angle (deg) & 128.9 & 129.2 & 128.3 \\
\hline $\begin{array}{l}\text { Lower anterior facial } \\
\text { height }(\mathrm{mm})\end{array}$ & 81.3 & 76.2 & 76.4 \\
\hline Y axis (deg) & 70.1 & 58.5 & 62.1 \\
\hline \multicolumn{4}{|l|}{ 3. Dental relation } \\
\hline Incisor overbite (mm) & -2.4 & 1.9 & 3.2 \\
\hline Incisor overjet (mm) & 7.8 & 3.9 & 3.7 \\
\hline \multicolumn{4}{|l|}{ 4. Soft T. relation } \\
\hline Nasolabial angle (deg) & 99.1 & 108.8 & 93.5 \\
\hline Upper lip to E-line (mm) & 2.3 & -2.1 & -0.6 \\
\hline Lower lip to E-line (mm) & 6.8 & 11.5 & 4.6 \\
\hline
\end{tabular}

As the mandible is a floating bone suspended by the peroral muscle group, the relative position of the mandible is determined by the balance among the groups [16]. Class II open-bite patients show a small volume of mouth closing muscles and well-developed suprahyoid muscle groups [17]. Ramus surgery for the counterclockwise rotation of the mandible increases the tension on the suprahyoid muscle groups [18]. This tension is considered a major etiologic factor for post-operative relapse $[18,19]$. The relapse rate of class II open bite after orthognathic surgery varies considerably from 1.5 to $42.9 \%$ [20-24]. Actual amount of relapse may depend on the orthodontic
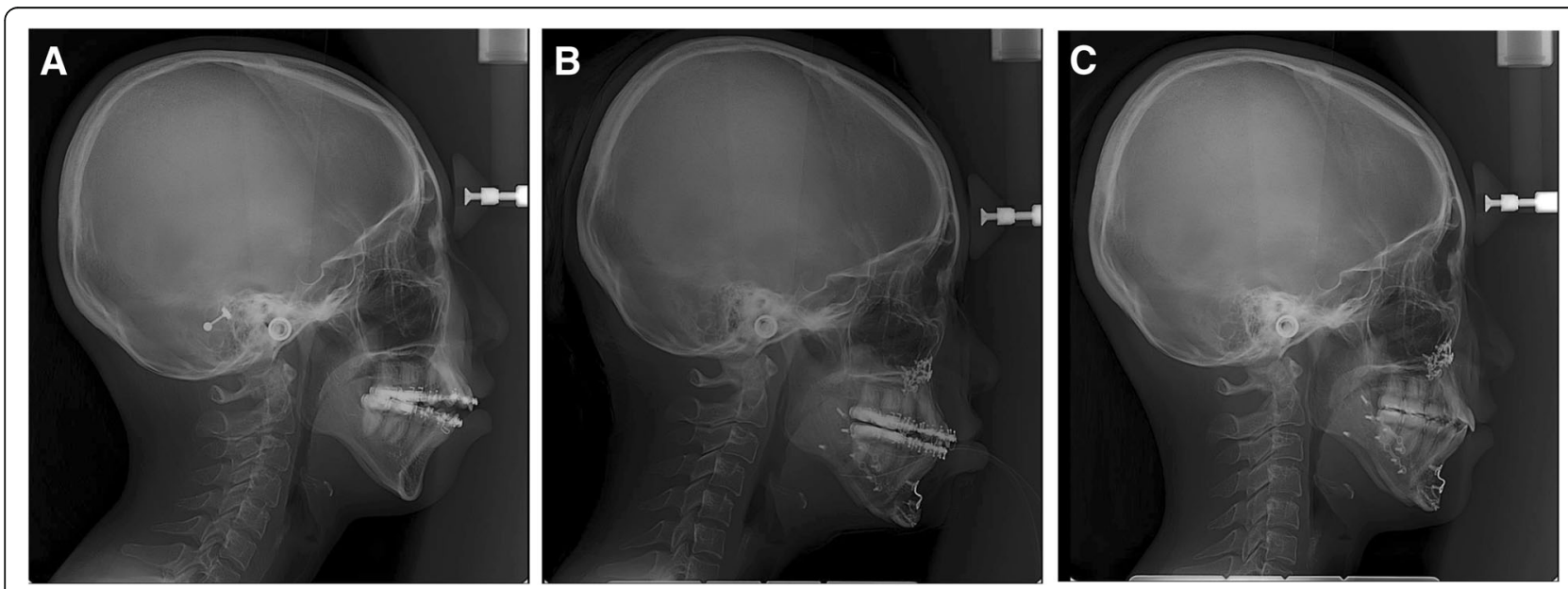

Fig. 2 Lateral cephalograms before surgery (a), immediately after surgery (b), and 15 months after surgery (c). In this case, BTX-A injection into the anterior belly of the digastric muscle seemed to prevent post-operative open bite. The patient's overbite was successfully maintained for 15 months post-operatively. The SNB angle and mandibular plane angle were also stable post-operatively 
treatment, fixation method, intermaxillary fixation period, osteotomy design, and additional therapy such as myotomy [3-6]. Some procedures such as the fixation method and the intermaxillary fixation period are designed to resist muscle power [4-6]. Posterior impaction of LeFort I osteotomy during surgery reduces the amount of mandibular counterclockwise rotation [25]. As relapse is associated with the correction amount, reduced counterclockwise rotation may be helpful for preventing post-operative relapse [25].

Procedures such as myotomy are designed to reduce muscle power [3]. The rationale for myotomy is similar to BTX-A injection. According to animal study, suprahyoid myotomy group shows less skeletal relapse compared to non myotomy group at 2 years post-operatively [26]. In this paper, pulling action of the suprahyoid musculature is a major risk causing factor in class II open-bite patients [26]. However, a multi-institutional study of 87 individuals did not prove the effectiveness of the suprahyoid myotomy in preventing skeletal relapse [27].

As a complication, anterior open bite has been frequently observed after bilateral mandibular angle fracture [28]. Bilateral mandibular angle fractures result in discontinuity between the mouth opening muscles and the mouth closing muscles [11]. The muscles responsible for opening the mouth are mainly attached to the mandibular anterior region and those for closing the mouth to the mandibular ramus [11]. Accordingly, the influence of the opening muscles is dominant in the mandibular anterior area [11]. BTX-A injection into the anterior belly of the digastric muscle could treat patients with anterior open bite after an open reduction in the bilateral mandibular angle fractures [11]. Radiofrequency therapy for the correction of post-traumatic open bite has similar mechanisms to BTX-A injection [28].

Based on these observations, BTX-A injection into the anterior belly of the digastric muscle was used for the positional stability of a class II open-bite patient who received orthognathic surgery. This study has limitations. First, this was a single case observation. For the stable occlusion after surgery, the importance of post-operative orthodontic treatment should not be ignored. The effect of a BTX-A single injection was difficult to quantify because of other contributing factors. Accordingly, a large-scale prospective study should be conducted for definite conclusions. In addition, there was no experimental support for this protocol. In order to embody the preciseness, the study should be designed and relevant data should be given to prove experimental conclusions. Second, the toxin dosage is very important to avoid any potential complications [29]. The optimal dosage should be tailored using follow-up research. However, BTX-A injection into the anterior belly of the digastric muscle is relatively safe and inexpensive compared to suprahyoid myotomy [15].

\section{Conclusions}

This single case presentation demonstrated that BTX-A injection into the anterior belly of the digastric muscle was used for the positional stability of a class II open-bite patient who received orthognathic surgery. If the correct procedure is performed without abuse, BTX-A injection can be a primary option for the prevention of post-operative relapse.

\section{Abbreviation}

BTX: Botulinum toxin

\section{Acknowledgments \\ None.}

\section{Funding}

This work was carried out with the support of "Cooperative Research Program for Agriculture Science and Technology Development (Project no. PJ01313902)" Rural Development Administration, Republic of Korea.

Availability of data and materials

All datasets used in this study were shown in this paper.

Authors' contributions

This study was designed by KYJ and KSG. CBK, CDS, and JIS did pre- and post-operative orthodontic treatment and associated analysis. KYJ and KSG wrote the manuscript and performed the critical review. All authors read and approved the final manuscript.

\section{Ethics approval and consent to participate}

Retrospective data collection was approved by the institutional review board of Gangneung-Wonju National University Dental Hospital (IRB No. 2019-001).

\section{Consent for publication}

This manuscript does not contain any individual person's identifier (including individual details, images or videos).

\section{Competing interests}

The authors declare that the authors have no competing interests as defined by Nature Research, or other interests that might be perceived to influence the results and/or discussion reported in this paper. KSG is an editorial board member of "Maxillofacial Plastic and Reconstructive Surgery."

\section{Publisher's Note}

Springer Nature remains neutral with regard to jurisdictional claims in published maps and institutional affiliations.

\section{Author details}

'Department of Oral and Maxillofacial Surgery, College of Dentistry, Gangneung-Wonju National University, Gangneung 28644, Republic of Korea. ${ }^{2}$ Department of Orthodontics, College of Dentistry, Gangneung-Wonju National University, Gangneung 28644, Republic of Korea.

Received: 22 January 2019 Accepted: 21 March 2019

Published online: 26 April 2019

\section{References}

1. Craig CE (1951) The skeletal patterns characteristic of class I and class II, division I malocclusions in norma lateralis. The Angle Orthodontist 21(1):4456

2. Proffit WR, Bailey LTJ, Phillips C, Turvey TA (2000) Long-term stability of surgical open bite correction by Le fort I osteotomy. The Angle Orthodontist 70(2):112-117

3. Carlson DS, Ellis E, Dechow PC, Nemeth PA (1989) Short-term stability and muscle adaptation after mandibular advancement surgery with and without suprahyoid myotomy in juvenile Macaca mulatta. Oral surgery, oral medicine, oral pathology 68(2):135-149 
4. Sato FRL, Asprino L, Moreira RWF, de Moraes M (2014) Comparison of postoperative stability of three rigid internal fixation techniques after sagittal split ramus osteotomy for mandibular advancement. J CranioMaxillofac Surg 42(5):e224-e229

5. Chuong C-J, Borotikar B, Schwartz-Dabney C, Sinn DP (2005) Mechanical characteristics of the mandible after bilateral sagittal split ramus osteotomy: comparing 2 different fixation techniques. J Oral Maxillofac Surg 63(1):68-76

6. Brasileiro BF, Grempel RG, Ambrosano GMB, Passeri LA (2009) An in vitro evaluation of rigid internal fixation techniques for sagittal split ramus osteotomies: advancement surgery. J Oral Maxillofac Surg 67(4): 809-817

7. Papageorge MB, Doku HC (1987) Postoperative infection following suprahyoid myotomy performed in conjunction with sagittal osteotomy of the mandible: report of a case. J Oral Maxillofac Surg 45(5):460-462

8. Marchese-Ragona R, Marioni G, Restivo DA, Staffieri A (2006) The role of botulinum toxin in postparotidectomy fistula treatment. A technical note. Am J Otolaryngol 27(3):221-224

9. Mahant N, Clouston P, Lorentz I (2000) The current use of botulinum toxin J Clin Neurosci 7(5):389-394

10. Song P, Schwartz J, Blitzer A (2007) The emerging role of botulinum toxin in the treatment of temporomandibular disorders. Oral Dis 13(3):253-260

11. Seok H, Park Y-T, Kim S-G, Park Y-W (2013) Correction of post-traumatic anterior open bite by injection of botulinum toxin type a into the anterior belly of the digastric muscle: case report. J Korean Assoc Oral Maxillofac Surg 39(4):188-192

12. Park S-Y, Park Y-W, Ji Y-J, Park S-W, Kim S-G (2015) Effects of a botulinum toxin type a injection on the masseter muscle: an animal model study. Maxillofacial plastic and reconstructive surgery 37(1):10

13. Moore A, Wood G (1994) The medical management of masseteric hypertrophy with botulinum toxin type a. Br J Oral Maxillofac Surg 32(1):26-28

14. Tabrizi R, Nili M, Aliabadi E, Pourdanesh F (2017) Skeletal stability following mandibular advancement: is it influenced by the magnitude of advancement or changes of the mandibular plane angle? J Korean Assoc Oral Maxillofac Surg 43(3):152-159

20. Denison TF, Kokich VG, Shapiro PA (1989) Stability of maxillary surgery in open bite versus non-open bite malocclusions. The Angle Orthodontist 59(1):5-10

21. Fischer K, von Konow L, Brattström V (2000) Open bite: stability after bimaxillary surgery-2-year treatment outcomes in 58 patients. The European Journal of Orthodontics 22(6):711-718

22. Burden D, Johnston C, Kennedy D, Harradine N, Stevenson M (2007) A cephalometric study of class II malocclusions treated with mandibular surgery. Am J Orthod Dentofac Orthop 131(1):7. e1-7. e8

23. Ito G, Koh M, Fujita T, Shirakura M, Ueda H, Tanne K (2014) Factors related to stability following the surgical correction of skeletal open bite. Australian orthodontic journal 30(1):61

24. Schwartz K, Rodrigo-Domingo M, Jensen T (2016) Skeletal stability after large mandibular advancement (> $10 \mathrm{~mm}$ ) with bilateral sagittal split osteotomy and skeletal elastic intermaxillary fixation. Journal of oral \& maxillofacial research 7(2):e5

15. Jaspers GWC, Pijpe J, Jansma J (2011) The use of botulinum toxin type a in cosmetic facial procedures. Int J Oral Maxillofac Surg 40:127-133

16. Ferré JC, Barbin JY, Helary JL, Lumineau JP (1984) The mandible, an overhanging mechanically suspended structure. Considerations on the system of attachment and servo-command of the mandible. Clin Anat 6(1):3-10

17. Yousefzadeh F, Shcherbatyy V, King GJ, Huang GJ, Liu ZJ (2010) Cephalometric and electromyographic study of patients of east African ethnicity with and without anterior open bite. Am J Orthod Dentofac Orthop 137(2):236-246

19. Sesenna E, Raffaini M (1985) Bilateral condylar atrophy after combined osteotomy for correction of mandibular retrusion. A case report. J Oral Maxillofac Surg 13(6):263-266

18. Karacay S, Gokce S, Yildirim E (2012) Evaluation of hyoid bone movements in subjects with open bite: a study with real-time balanced turbo field echo cine-magnetic resonance imaging. Korean Journal of Orthodontics 42(6):318-328

25. Ayoub AF, Trotman CA, Stirrups DR, Wilmot JJ (1997) Stability of bimaxillary osteotomy following surgical correction of class II skeletal deformities: a two-Centre study. Br J Oral Maxillofac Surg 35(2):107-115
26. Ellis E 3rd, Carlson DS (1983) Stability two years after mandibular advancement with and without suprahyoid myotomy: an experimental study. J Oral Maxillofac Surg 41(7):426-437

27. Schendel SA, Epker BN (1980) Results after mandibular advancement surgery: an analysis of 87 cases. J Oral Surg 38(4):265-282

28. Choi S-S, Rotaru H, Kim S-G (2007) Treatment of post-traumatic open bite by radiofrequency. Br J Oral Maxillofac Surg 45(4):311-313

29. Cohen JL, Scuderi N (2017) Safety and patient satisfaction of abobotulinumtoxinA for aesthetic use: a systematic review. Aesthet Surg J 37(S1):S32-S44

\section{Submit your manuscript to a SpringerOpen ${ }^{\circ}$ journal and benefit from:}

- Convenient online submission

- Rigorous peer review

- Open access: articles freely available online

- High visibility within the field

- Retaining the copyright to your article

Submit your next manuscript at $\boldsymbol{\nabla}$ springeropen.com 